\title{
Tympanoplasty in children: A review of 91 cases
}

\author{
Joao Carlos Ribeiro*, Cerejeira Rui, Silvestre Natercia, Romao Jose, Paiva Antonio \\ ORL-HUC, Praceta Mota Pinto, 3000-059 Coimbra, Portugal
}

Received 15 October 2009; accepted 26 May 2010

Available online 18 June 2010

\begin{abstract}
Objectives: There is a marked diversity in the reported success rates for achieving an intact tympanic membrane following tympanoplasty. Controversy exists about the factors thought to influence surgical outcome. These facts have important implications for the selection of patients who would benefit the most. This study reviews the factors thought to determine the anatomical and functional success of tympanoplasty in children.

Materials and methods: Retrospective study of the anatomical and functional results of 91 tympanoplasties performed in children. Age, gender, size and site of perforation, status of operated and contralateral ear, underlying cause of the perforations, surgical technique, preoperative and post-operative hearing levels, post-operative follow-up time and post-operative complications were recorded. We divided our population into two groups according to the expected eustachian tube maturity (younger group $(N=24)$ : $\leq 10$ years old, older group $(N=67)$ : $>10$ years old). All patients were evaluated in terms of anatomical and functional outcome and complications.

Results: Anatomical success was achieved in $85.7 \%$ and functional success was $76.9 \%$ after a mean follow-up of $25.6 \pm 17.1$ months. Anatomical success (intact tympanic membrane) was achieved in $83 \%$ of younger vs $87 \%$ of older patients $(p=$ n.s.). Functional (air bone gap closure) success was $75 \%$ in the younger group vs $78 \%$ in the older group ( $p=n$. .). There were no significant differences in post-operative gain at different frequencies $(500,1000,2000$ and $3000 \mathrm{~Hz})$ between the two groups. A previous adenoidectomy in children older than 10 years seems to be an independent predictor of functional success The incidence of minor and major complications were $29 \%$ in patients aged $\leq 10$ and $21 \%$ in those older than 10 ( $p=$ n.s.). We report $12.9 \%$ minor post-operative complications in successful cases: injury to the chorda tympani nerve $(5.7 \%)$, wound infection (2.9\%), otitis externa (2.9\%) and transient vertigo (1.4\%). Among the 21 reperforations observed, $92.3 \%$ occurred before 1 year.

Conclusions: This study shows that tympanoplasty is a valid treatment modality for tympanic membrane perforation in the pediatric population. A tympanic membrane perforation can be closed at any age. There is no age limit below which perforation should not be closed. A previous adenoidectomy in children older than 10 years seems to be an independent predictor of functional success.
\end{abstract}

(C) 2010 Elsevier Ireland Ltd. All rights reserved.

Keywords: Tympanoplasty; Outcome; Child; Graft integrity; Predictive factors; Adenoidectomy

\section{Introduction}

Tympanic membrane perforation is a known sequel of otitis media in children.

Deciding which patients benefit from surgical repair and when is the optimal age to perform it continues to be widely debated.

We used the definition of tympanoplasty type 1 according to Portmann [1].

\footnotetext{
* Corresponding author. Tel.: +351 239400450.

E-mail address: jcarlosribeiro@gmail.com (J.C. Ribeiro).
}

The success rates of tympanoplasties in children reported in literature vary from $35 \%$ [2] to $92 \%[3,4]$ (Table 1).

Tympanoplasties performed in children are reported as less successful than those performed in adults $[15,16]$. Problems associated with auditory tube dysfunction and the higher incidence of otitis media may be the reason for the evocated poorer tympanoplasty outcomes in children than those in adults $[9,15]$.

Many factors may influence the surgical outcome of tympanoplasty in children, such as age, the size and location of perforation, status of the operated and contralateral ear, 
Table 1

Success rates of tympanoplasty in children.

\begin{tabular}{lcccc}
\hline Author & $n$ & $\begin{array}{l}\text { Age } \\
\text { (years) }\end{array}$ & $\begin{array}{l}\text { Follow-up } \\
\text { (months) }\end{array}$ & $\begin{array}{l}\text { Success } \\
\text { rate (\%) }\end{array}$ \\
\hline Denoyelle et al. [5] & 231 & $4-17$ & 36 & 83 \\
Kessler et al. [4] & 209 & $<18$ & 6 & 92 \\
Ophir et al. [6] & 172 & $5-12$ & 12 & 79 \\
Lau and Tos [3] & 155 & $2-14$ & 36 & 92 \\
Buchwach and Birck [7] & 134 & $3-17$ & 24 & 66 \\
Raine and Singh [8] & 114 & $7-16$ & 36 & 72 \\
Black et al. [9] & 100 & $2-17$ & 24 & 75 \\
Koch et al. [10] & 64 & $2-17$ & 24 & 73 \\
Manning et al. [11] & 63 & $5-19$ & 60 & 78 \\
Vartiainen and Nuutinen [12] & 60 & $<18$ & 60 & 90 \\
Blanchard et al. [13] & 59 & $<14$ & 180 & 78 \\
Caylan et al. [14] & 51 & $5-16$ & 18 & 82 \\
Bluestone et al. [2] & 45 & $2-16$ & 24 & 35 \\
\hline
\end{tabular}

presence of hypertrophic adenoids, function of the auditory tube and surgeons' experience $[10,15,17]$.

We aim to find which patients will benefit the most from tympanoplasty and when is the optimal age to perform it.

\section{Population and methods}

Retrospective case series review of 91 ears from patients younger than 18 years old who underwent a primary tympanoplasty type 1 [1] without mastoidectomy in our department between January 1986 and December 2006.

We considered only those with a dry ear over 6 months, who underwent a primary tympanoplasty and were followed up for at least 6 months.

Patient's age at surgery, gender, size, side and location of perforation in the tympanic membrane, status of the operated and contralateral ear, history of previous otolaryngology surgery, auditory tube dysfunction, pre-operative and post-operative hearing levels, length of follow-up and post-operative complications were recorded.

All cases with the presence of cholesteatoma, tympanosclerosis, immune deficiency, metabolic diseases, malignancy and mental retardation were excluded.

The information of perforation size was obtained from sketches and intraoperative descriptions. Size of the perforation was classified as either more or less than $50 \%$ of the total surface area of the tympanic membrane.

Regarding the location of perforations they were classified as anterior or posterior if they were anterior or posterior to the long process of malleus, respectively.

If an anterior perforation extended posteriorly to the long process of malleus, it was considered as central. Perforations were considered as inferior if they were inferior to the umbus of malleus and considered as marginal when concerning annulus tympanicus.

Regarding the status of the operated and contralateral year, we reported the presence of infection, otorrhea, effusion, tympanostomy tubes or atelectasis.
Previous otolaryngology surgery was recorded, namely transtympanic tube placement surgery and adenoidectomy.

All children were submitted to general anesthesia. All tympanoplasties were performed using an underlay technique with temporalis fascia grafting via a transcanal or postauricular approach.

Routine prophylactic antibiotic therapy was given to all patients.

Children underwent tympanometry as a tool to evaluate auditory tube dysfunction.

All patients underwent pre- and post-operative audiological evaluation, including hearing threshold at $0.5,1,2$ and $4 \mathrm{kHz}$, permitting to assess functional success. The thresholds at $3 \mathrm{kHz}$ were estimated as the means of the thresholds at 2 and $4 \mathrm{kHz}$.

We reported the air-bone gap as the four-tone pure-tone average for air conduction minus the same average for bone conduction determined at the same time. The mean and standard deviation of the post-operative air-bone gap and number of decibels of closure of the air-bone gap were reported according to the recommendations of the Committee on hearing and Equilibrium Guidelines for the evaluation of results of treatment of conductive hearing loss [18].

Anatomical success was defined as the presence of an intact graft evaluated by microscopy and/or tympanometry without perforation, atelectasy or lateralization at the last follow-up visit with a minimum of 6 months.

Functional success was defined as a post-operative air bone gap $(0.5-3 \mathrm{kHz})<20 \mathrm{~dB}$ according to the Committee on Hearing and Equilibrium Guidelines for the evaluation of results of treatment of conductive hearing loss [18].

We divided our population into two groups according to the expected eustachian tube maturity [older group $(N=24)$ : $\leq 10$ years old, younger group $(N=67):>10$ years old] [19-21].

This study has been conducted according to Declaration of Helsinki principles.

Statistical analyses were performed using SPSS release 16 software.

Results were expressed as mean \pm standard deviation for continuous variables and as percentage for categorical variables.

Patients and tympanic perforation characteristics were compared with the student $\mathrm{t}$ test or a Mann-Whitney and a chi-square test when appropriate.

The multivariate logistic regression analysis was used to try to identify independent predictors of functional success in the overall population, in those $\leq 10$ years old and in those $>10$ years old. We included the following variables in the models: age, size of the perforation, status of contralateral ear and surgeons' experience. $p<0.05$ was considered statistically significant. 
Table 2

Mean gain at different frequencies.

\begin{tabular}{|c|c|c|c|c|}
\hline \multirow{2}{*}{$\begin{array}{l}\text { Audiometric } \\
\text { Rinne }(\mathrm{kHz})\end{array}$} & \multirow[t]{2}{*}{ Mean } & \multicolumn{2}{|c|}{ Confidence interval $95 \%$} & \multirow[t]{2}{*}{$p$} \\
\hline & & Inferior & Superior & \\
\hline 0.5 & 14.95 & 12.83 & 17.06 & 0.02 \\
\hline 1 & 13.13 & 11.03 & 15.24 & 0.02 \\
\hline 2 & 10.93 & 9.03 & 12.83 & 0.03 \\
\hline 3 & 11.48 & 9.46 & 13.51 & 0.03 \\
\hline
\end{tabular}

\section{Results}

We report complete data in 91 ears of 79 patients. In 12 patients, we performed a bilateral staged procedure.

The mean age was $12.0 \pm 3.1$ years old (range 6-17 years). Thirteen patients $(14.3 \%)$ were $\leq 8$ years old. Fortythree percent were female and $57 \%$ male. Fifty-three percent were left ears and $47 \%$ right ears.

Regarding previous ORL surgery, $32 \%$ were submitted to transtympanic tube placement surgery.

An anatomical success was achieved in $85.7 \%$ of cases, at the last follow-up visit.

The mean pre-operative and post-operative bone threshold was $1.3 \pm 4.1$ and $1.2 \pm 3.2 \mathrm{~dB}$. The mean pre-operative and post-operative air threshold was, respectively, $30.8 \pm 11.0$ and $18.2 \pm 10.5 \mathrm{~dB}$, with a mean audiological improvement of $12.6 \pm 9.9 \mathrm{~dB} \quad(p<0.05)$. The best

Table 3

Functional success at different ages.

\begin{tabular}{|c|c|c|c|c|}
\hline & & & \multicolumn{2}{|c|}{ Functional success } \\
\hline & & & Insuccess & Success \\
\hline \multirow[t]{16}{*}{ Age } & 6 & $n$ & 0 & 2 \\
\hline & & $\%$ within age & $0 \%$ & $100 \%$ \\
\hline & 7 & $n$ & 1 & 5 \\
\hline & & $\%$ within age & $16.7 \%$ & $83.3 \%$ \\
\hline & 8 & $n$ & 1 & 4 \\
\hline & & $\%$ within age & $20 \%$ & $80 \%$ \\
\hline & 9 & $n$ & 4 & 7 \\
\hline & & $\%$ within age & $36.4 \%$ & $63.6 \%$ \\
\hline & 10 & $n$ & 1 & 5 \\
\hline & & $\%$ within age & $16.7 \%$ & $83.3 \%$ \\
\hline & 11 & $n$ & 2 & 10 \\
\hline & & $\%$ within age & $16.7 \%$ & $83.3 \%$ \\
\hline & 12 & $n$ & 1 & 6 \\
\hline & & $\%$ within age & $14.3 \%$ & $85.7 \%$ \\
\hline & 13 & $n$ & 4 & 7 \\
\hline & & $\%$ within age & $36.4 \%$ & $63.6 \%$ \\
\hline \multirow[t]{8}{*}{ Age } & 14 & $n$ & 3 & 5 \\
\hline & & $\%$ within age & 37.5 & 62.5 \\
\hline & 15 & $n$ & 0 & 9 \\
\hline & & $\%$ within age & $0 \%$ & $100 \%$ \\
\hline & 16 & $n$ & 2 & 4 \\
\hline & & $\%$ within age & $33.3 \%$ & $66.7 \%$ \\
\hline & 17 & $n$ & 2 & 6 \\
\hline & & $\%$ within age & $25 \%$ & $75 \%$ \\
\hline \multirow[t]{2}{*}{ Total } & & $n$ & 21 & 70 \\
\hline & & $\%$ & $23.1 \%$ & $76.9 \%$ \\
\hline
\end{tabular}

Table 4

Size, location and side of perforations.

\begin{tabular}{lrcc}
\hline & $n$ & $\begin{array}{l}\text { Anatomical } \\
\text { success }(\%)\end{array}$ & $\begin{array}{l}\text { Functional } \\
\text { success }(\%)\end{array}$ \\
\hline Location & & & \\
Central & 52 & 90.4 & 80.8 \\
Anterior & 9 & 88.9 & 88.9 \\
Inferior & 6 & 50 & 33.3 \\
Posterior & 3 & 100 & 66.7 \\
Marginal & 21 & 81 & 80.3 \\
Size & & & 68 \\
$<50 \%$ & 66 & 86.4 & 74.3 \\
$>50 \%$ & 25 & 84 & 72.1 \\
Side & & & \\
Left & 48 & 76.7 & \\
Right & 43 & &
\end{tabular}

improvement was observed at the frequency of $0.5 \mathrm{kHz}$ $(14.95 \pm 10.18 \mathrm{~dB})$ (Table 2). There were no significant differences in the post-operative gain at all frequencies between the younger and older group.

The overall functional success was $76.9 \%$ (70/91). The functional success rate was $78.5 \%$ in patients with monolateral disease and $69.8 \%$ in those with bilateral perforation $(p=$ n.s.). We observed $30.7 \%$ cases with air bone gap closure $<10 \mathrm{~dB}, 46.2$ between 11 and $20 \mathrm{~dB}$, $13.2 \%$ between 21 and $30 \mathrm{~dB}$ and $9.8 \%>31 \mathrm{~dB}$.

Anatomical success was achieved in $83 \%$ of younger vs $87 \%$ of older patients ( $p=$ n.s.). Functional success was $75 \%$ in the younger group vs $78 \%$ in the older group ( $p=$ n.s.).

We present the raw data of functional success divided by yearly groups in Table 3 .

We present the anatomical and functional success results regarding the size, location and size of pre-operative perforations in Table 4.

Forty-six percent of our population underwent a previous adenoidectomy (Table 5).

Table 5

Previous adenoidectomy, auditory tube function and contralateral ear status ( $n=91 ; p$ values about functional success).

\begin{tabular}{|c|c|c|c|c|c|}
\hline & & \multirow[t]{2}{*}{$n$} & \multirow[t]{2}{*}{$\begin{array}{l}\text { Anatomical } \\
\text { success }\end{array}$} & \multicolumn{2}{|c|}{$\begin{array}{l}\text { Functional } \\
\text { success }\end{array}$} \\
\hline & & & & $\%$ & $p$ \\
\hline \multicolumn{6}{|c|}{ Adenoidectomy } \\
\hline \multirow[t]{2}{*}{ All $(n=91)$} & Yes & 42 & $93 \%$ & 86 & 0.07 \\
\hline & No & 49 & $80 \%$ & 70 & \\
\hline \multirow[t]{2}{*}{$>10$ years } & Yes & 31 & $97 \%$ & 90 & 0.02 \\
\hline & No & 36 & $78 \%$ & 67 & \\
\hline \multirow[t]{2}{*}{$\leq 10$ years } & Yes & 11 & $82 \%$ & 73 & 0.08 \\
\hline & No & 13 & $85 \%$ & 77 & \\
\hline \multicolumn{6}{|c|}{ Auditory tube function } \\
\hline \multicolumn{2}{|l|}{ Impaired } & 61 & $89 \%$ & $87 \%$ & 0.06 \\
\hline \multicolumn{2}{|l|}{ Normal } & 30 & $80 \%$ & $60 \%$ & \\
\hline \multicolumn{6}{|c|}{ Contralateral ear status } \\
\hline \multicolumn{2}{|l|}{ Abnormal } & 53 & 83 & 82 & 0.11 \\
\hline \multicolumn{2}{|l|}{ Normal } & 38 & 89 & 74 & \\
\hline
\end{tabular}


Table 6

Surgeons experience.

\begin{tabular}{lllll}
\hline & $n$ & $\begin{array}{l}\text { Anatomical } \\
\text { success }(\%)\end{array}$ & $\begin{array}{l}\text { Functional } \\
\text { success }(\%)\end{array}$ & $p$ \\
\hline Resident & 17 & 82 & 82 & $>0.05$ \\
Consultant & 74 & 86 & 76 & $>0.05$ \\
\hline
\end{tabular}

There were no statistical differences between the group previously submitted to adenoidectomy and the other group regarding anatomical and functional success. Interestingly, the subgroup of children older than 10 years old submitted to adenoidectomy showed a significantly higher functional success than those not previously submitted to adenoidectomy, which was confirmed by the multivariate logistic regression analysis.

The average follow-up time was $25.6 \pm 17.1$ months.

In our study, a non-significant difference of surgical success between senior and junior surgeons was reached (Table 6).

We report $12.9 \%$ minor post-operative complications in successful cases: injury to the chorda tympani nerve (5.7\%), wound infection $(2.9 \%)$, otitis externa $(2.9 \%)$ and transient vertigo $(1.4 \%)$.

We observed eight cases that achieved anatomical success without functional success. No statistical difference was observed regarding age, minor complications or the other characteristics analyzed between these patients and those with functional success.

Among the 21 reperforations observed, $92.3 \%$ occurred before 1 year, being $84.6 \%$ before 3 months of follow up.

The incidence of complications were $29 \%$ in patients aged $\leq 10$ and $21 \%$ in those older than 10 ( $p=$ n.s.).

In the multivariate logistic regression analysis, we could not find independent predictors of functional success in both the overall population and in the population $\leq 10$ years old. However, in the population $>10$ years old, a previous adenoidectomy was identified as the only independent predictor of functional success (OR: 4.9, CI 95\%: 1.06122.21).

\section{Discussion}

The disparity of surgical outcome in pediatric tympanoplasty is partly explained by differences in the inclusion and exclusion criteria and definitions of success. Some studies have included patients with middle ear diseases and other co-morbidities that can be confounding variables.

Most studies used the anatomical criteria of success. However, a normally functioning middle ear after tympanoplasty clearly requires more than an intact graft. A stricter definition of success is used according to the American Academy of Otolaryngology Head and Neck Surgery guidelines [18]. In general, investigators who use the strictest criteria usually report lower success rates [7-10].
We found anatomical and functional success rates similar to others in literature (85.7\% and $76.9 \%$, respectively) $[2,3,16,17,10,11]$ Table 1.

The evidence of a good audiological result in anatomically successful cases is associated with a highly probable return to normal function and lifestyle at any age.

Age is often cited as a key prognostic factor in evaluation for tympanoplasty in children [15,19,22,23].

Literature reports contradictory results. Some authors observed that an older age was associated with better results $[15,24]$. Other authors have reported no significant correlation between age and surgical outcome [14,25].

In the present study, younger and older children had similar success rates. A younger age was not a prognostic variable $(p>0.05)$.

Even though reperforation was more frequent in inferior and marginal perforations (Table 4), no statistical correlation was found between the location of the initial perforation and the occurrence of reperforation ( $p=$ n.s.), as previously reported by others $[4,5,10,14]$. While some reported worse results with posterior perforations [26,27], we had only three cases, but all of them successful.

Because tympanic membrane must heal by secondary intention, the size of the perforation may influence the results [26,27]. Although we report a tendency of larger perforations to have worse results than smaller ones Table 5 (68\% vs $80.3 \%, p>0.05)$, the size of pre-operative perforation did not correlate with functional success, similarly to other studies $[5,9,12,13,25]$.

Adenoidectomy can lessen the incidence of otitis media with effusion and, therefore, may be associated with a lower incidence of recurrent tympanic perforation [25].

We found higher tympanoplasty success rates in patients previously treated with adenotonsillectomy or adenoidectomy, but without statistical significance, a result in line with those published by others [2,7,15,25].

Surprisingly, within the older group, when comparing patients submitted to adenoidectomy or not, those previously submitted to adenoidectomy showed higher success rates, contrary to what was expected. Multivariate analysis confirmed previous adenoidectomy as an independent predictor of functional success in that population. One possible explanation is that all these patients had a normal tubal function without adenoid hypertrophy thus leading to a better tubal function.

If the patient's better ear is clinically normal, then tympanoplasty in the contralateral ear will probably be successful. In our study, auditory tube function and the status of contralateral ear were not significant predictors of success in pediatric tympanoplasty.

Literature shows that the experience of the surgeon on tympanoplasty operations has not been stressed thoroughly. While significantly better results are obtained by senior surgeons, technical skill and attention to detail varies among clinicians in a manner that is not strictly related to the level of training and experience [10,20]. In our study (Table 6), a 
non-significant difference of surgical success between senior and junior surgeons was reached, what could be explained by the fact that consultants always accompany residents during the entire surgery.

We observed eight cases that achieved anatomical success without functional success. We found no statistically significant differences between them and patients that achieved anatomical plus functional success, probably because of the reduced number of cases.

We stated that $84.6 \%$ of reperforations occurred before 3 months of follow up, most likely because of an inappropriate surgical technique.

The functional success rate was $78.5 \%$ in our cases with monolateral disease and $69.8 \%$ in those with bilateral perforation $(p>0.05)$. This result resembles others in literature $[4,5]$.

We found no predictor factor of success in our study other than a previous adenoidectomy in children older than 10 years old.

Although every single factor related to the surgery and patients should be optimized, it is difficulty with clinical studies, even prospective ones, to control all patient factors.

This study shows some limitations. Our conclusions came after a retrospective review. On the other hand, not all patient factors can be independently controlled. A selection bias could have been done as several authors sustain that dry ears may have a negative effect on the outcome of tympanoplasty for patients with simple chronic otitis media $[12,28]$.

We introduce raw data, as a way not to miss a significant effect when one exists, which could be remedied by accumulating additional data on future meta-analysis.

\section{Conclusions}

This study shows that tympanoplasty is a valid treatment modality for tympanic membrane perforation in the pediatric population. A tympanic membrane perforation can be closed at any age. There is no age limit below which perforation should not be closed. A previous adenoidectomy in children older than 10 years seems to be an independent predictor of functional success.

\section{References}

[1] Portmann M. Les tympanoplasties simples. In: Portmann M, Guerrier Y, editors. Traité de Technique Chirurgicale ORL et Cervico-faciale. Paris: Masson; 1975.

[2] Bluestone C, Cantekin E, Douglas G. Eustachian tube function related to the results of tympanoplasty in children. Laryngoscope 1979;89: $450-8$.
[3] Lau T, Tos M. Tympanoplasty in children: an analysis of late results. Am J Otol 1986;7:55-9.

[4] Kessler A, Potsic W, Marsh R. Type 1 tympanoplasty in children. Arch Otolaryngol Head Neck Surg 1994;120:487-90.

[5] Denoyelle F, Roger G, Chauvin P, Garabedian EN. Myringoplasty in children:predictive factors of outcome. Laryngoscope 1999;109: 47-51.

[6] Ophir D, Porat M, Marshak G. Myringoplasty in the pediatric population. Arch Otolaryngol Head Neck Surg 1987;113.

[7] Buchwach K, Birck H. Serous otitis media and type I tympanoplasties in children. Ann Otol Rhinol Laryngol 1980;89(Suppl.):324-5.

[8] Raine C, Singh S. Tympanoplasty in children: a review of 114 cases. J Laryngol Otol 1983;97:217-21.

[9] Black J, Hickey S, Wormald P. An analysis of the results of myringoplasty in children. Int J Pediatr Otorhinolaryngol 1995;31:95-100.

[10] Koch W, Friedman E, McGill T, Healy GB. Tympanoplasty in children. The Boston Children's Hospital experience. Arch Otolaryngol Head Neck Surg 1990;116:35-40.

[11] Manning S, Cantekin E, Kenna M, Bluestone CD. Prognostic value of Eustachian tube function in pediatric tympanoplasty. Laryngoscope 1987;97:1012-6.

[12] Vartianinen E, Nuutinen J. Success and pitfalls in myringoplasty: follow-up study of 404 cases. Am J Otol 1993;14:301-5.

[13] Blanshard J, Robson A, Smith I, Maw AR. A long term view of myringoplasty in children. J Laryngol Otol 1990;104:758-62.

[14] Caylan R, Titiz A, Falconi M, Donato G, Russo A, Taibah A, et al. Myringoplasty in children: factors influencing surgical outcome. Otolaryngol Head Neck Surg 1998;118:709-13.

[15] Vrabec J, Deskin R, Grady J. Meta-analysis of pediatric tympanoplasty. Arch Otolaryngol Head Neck Surg 1999;125:530-4.

[16] Shih L, Tar TD, Crabtree J. Myringoplasty in children. Otolaryngol Head Neck Surg 1991;105:74-7.

[17] Raine C, Singh S. Tympanoplasty in children: a review of 472 cases. Ann Otol Rhinol Laryngol 1980;89:331-4.

[18] Committee on hearing and equilibrium guidelines for the evaluation of results of treatment of conductive hearing loss. Otolaryngol Head Neck Surg 1995;113:186-8.

[19] Lin A, Messner A. Pediatric tympanoplasty: factors affecting success. Curr Opin Otol 2008;16:64-8.

[20] Emir H, Ceylan K, Kizilkaya Z. Success is a matter of experience: type 1 tympanoplasty: influencing factors on type 1 tympanoplasty. Eur Arch Otorhinolaryngol 2007;264:595-9.

[21] Mak D, Mackendrick A, Bulsara M, Coates H, Lannigan F, Lehman D, et al. Outcomes of myringoplasty in Australian aboriginal children and factors associated with success: A prospective case series. Clin Otolaryngol Allied Sci 2004;29:606-11.

[22] Yung M, Neumann C, Vowler S. A longitudinal study on pediatric myringoplasty. Otol Neurotol 2007;28:353-5.

[23] Gupta N, Mishra R. Tympanoplasty in children. Indian J Otol Head and Neck Surg 2002;54:271-3.

[24] Chandrasekhar S, House J, Devgan U. Pediatric tympanoplasty: a 10year experience. Arch Otolaryngol Head Neck Surg 1995;121:873-8.

[25] Vartiainen E, Vartiainen J. Tympanoplasty in young patients: the role of adenoidectomy. Otolaryngol Head Neck Surg 1997;117:583-8.

[26] Lee P, Kelly G, Mills R. Myringoplasty: does the size of the perforation matter? Clin Otolaryngol 2002;27:331-4.

[27] Yung M. Myringoplasty: hearing gain in relation to perforation site. J Laryngol Otol 1983;97:11-7.

[28] Albera R, Ferrero V, Lacilla M, Canale A. Tympanic reperforation in myringoplasty: evaluation of prognostic factors. Ann Otol Rhinol Laryngol 2006;115:875-9. 